\title{
On the processes which take place at the boundary between two solutions of different concentration when a current is passed
}

\section{George H. Zahn}

To cite this article: George H. Zahn (1893) On the processes which take place at the boundary between two solutions of different concentration when a current is passed, Philosophical Magazine Series 5, 36:218, 151-152, DOI: 10.1080/14786449308620461

To link to this article: http://dx.doi.org/10.1080/14786449308620461

曲 Published online: 08 May 2009.

Submit your article to this journal $[\pi$

Џll Article views: 2

Q View related articles $\longleftarrow$ 
cancelled. In Table XXI., Section 6 , the ratio $k / \beta$ for $\mathrm{CO}_{2}$ is given as 4 instead of $2 \cdot 5$, the logarithm baving been copied in place of the number.

Melbourne, April 1893.

Yours obediently, William Sutherdand.

ON A REMARKABLE PHENOMENON OF OXIDATION OF PURE ALUMINICM WHEN IN CONTACT WITH MERCURY. BY E. 0 . ERDMANN.

As soon as the two metals are in actual contact, snow-white filiform or straw-shaped formations result, growing from the point of contact of the two metals, which in a few minutes acquire a length of 2 to 3 centim. Under the microscope they appear as tube-shaped or plate-shaped veils, of extreme delicacy and perfectly amorphous. If they are detached by tapping or shaking they look like lint. Chemical investigation shows that they consist of pure aluminium hydrate.

It is immaterial for the formation of this oxide whether the contact between the metals is effected by rubbing, or whether the surfaces are purified with hydrochloric acid or caustic soda, and subsequent washing with much water and drying with blottingpaper.

The cause of this peculiar oxidation might be sought for in :-

(1) The formation of an easily oxidizable amalgam of aluminium, which always forms at the surface of contact in the degree in which aluminium oxidizes in moist air.

(2) The electrolytic decomposition of a thin layer of water, which is condensed on the surfaces of the two metals which form the element.

(3) That the highly positive aluminium by contact with mercury acquires a greater affinity for oxygen, in the same manner as, according to Magnus, iron-filings do when hanging to a magnet.Physical Society of Berlin, November 18, 1892 ; from Wiedemann's Annalen, No. 1, 1893.

ON THE PROCESSES WHICH TAKE PLACE AT THE BOUNDARY BETWEEN TWO SOLUTIONS OF DIFEHRENT CONCENTRATION WHEN A CURRENT IS PASSED, BY GEORGE H. ZAHN.

The results of these experiments are stated by the author as follows. Besides the well-known formation of hydroxides of magnesium, calcium, and copper above the boundary of a dilute solution over a concentrated one of the same salt when an electrical current passes from the concentrated to the dilute solution, it is possible, when the concentrations are very different, to observe the formation of a solid with barium, strontium, alumininm, iron, manganese, and zinc in combination with several acids. Silver does not exhibit such a behaviour. In each case, even with silver, and with the salts of potassium and of sodium, which form readily 
soluble hydrates, an alkaline reaction is observed above the boundary in the dilute solution, even with no great difference of concentration when dimethyl-orange is present, but not with less sensitive reagents. Gmelin * found in the electrolysis of $\mathrm{Na}_{2} \mathrm{SO}_{4}$ in water, and of $\mathrm{CaN}_{2} \mathrm{O}_{6}$ in water, in the presence of tincture of mallow, that the formation of acid or of alkali started from the electrode, and proceeded slowly towards the boundary. Davy observed this also with $\mathrm{K}_{2} \mathrm{SO}_{4}$ in water and solution of litmus.

Observations made using the far more sensitive dimethyl-orange as reagent do not confrm this. A rapid alkalinity is observed about a millimetre above the boundary, and with great differences of concentration the reaction takes place as rapidly above the boundary as at the electrode.

As regards the cause of this deposition at the boundary, which was first observed by Faraday in the case of magnesium sulphate, G. Wiedemann $\dagger$ ascribes it to the different degrees of migration in the solutions. Kohlrausch $\ddagger$ has objected to this, that a difference-rate of migration of the two solutions can only affect the change of concentration at the boundary, but cannot produce any excess of one ion.

From Hittorf's numbers for the rate of migration, the following conclusions may be formed:-

The influence of dilution on the rate of migration is seen to differ with the nature of the electrolyte. In most cases the migration of the anion decreases with increasing dilution, that of the kation increases in the same degree. With chloride of potassium the rates of migration are independent of the concentration; with the nitrates of silver, potassium, and sodium, the migration of the anion increases with dilution, that of the kation decreases.

If now the processes above the boundary bad their origin in the difference of the values for the migration a formation of hydrate might take place in most cases, potassium chloride could show no change above the boundary independent of differences of concentration, or at any rate very small ones, while with nitrates of silver, potassium, and sodium a formation of acid is to be expected. But the experiments, using dimethyl-orange as a reagent, are in disagreement with this; for with the same direction of current chloride of potassium as well as the last-mentioned salts show the same behaviour above the boundary as the other solutions.

Hence there remains so far only Kohlrausch's explanation, which sees in the action of water in electrolysis the cause of the processes at the boundary, and according to which these phenomena must necessarily follow. It would be desirable that the experiments should be made on a sufficiently large scale to examine the products qualitatively and quantitatively.-Wiedemann's Annalen, No. 4, 1893.

* Wiedemann's Electricität, vol, ii. pp. 599 \& 614 .

$\dagger$ Electr. vol. ii. p. 607.

$\ddagger$ Wied. Ann. vol, xxvi. p. 210, 1885. 